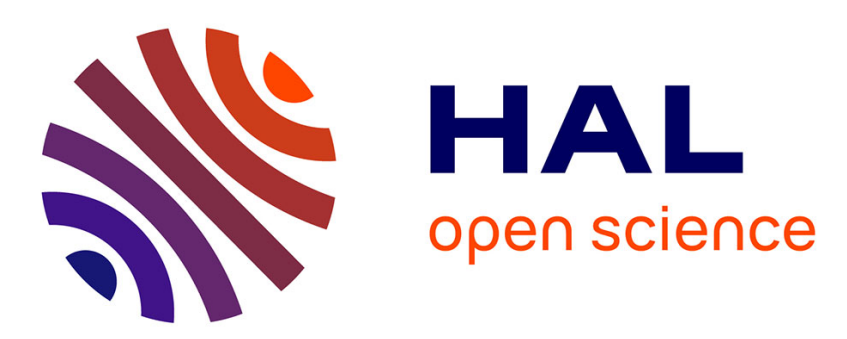

\title{
Influence of Composition and Plastic Deformation on the Hydrogen Internal Friction Peak in Amorphous Co-Zr Alloys
}

F. Winter, S. Adam, H.-R. Sinning

\section{- To cite this version:}

F. Winter, S. Adam, H.-R. Sinning. Influence of Composition and Plastic Deformation on the Hydrogen Internal Friction Peak in Amorphous Co-Zr Alloys. Journal de Physique IV Proceedings, 1996, 06 (C8), pp.C8-55-C8-58. 10.1051/jp4:1996810 . jpa-00254527

\section{HAL Id: jpa-00254527 https://hal.science/jpa-00254527}

Submitted on 1 Jan 1996

HAL is a multi-disciplinary open access archive for the deposit and dissemination of scientific research documents, whether they are published or not. The documents may come from teaching and research institutions in France or abroad, or from public or private research centers.
L'archive ouverte pluridisciplinaire HAL, est destinée au dépôt et à la diffusion de documents scientifiques de niveau recherche, publiés ou non, émanant des établissements d'enseignement et de recherche français ou étrangers, des laboratoires publics ou privés. 


\title{
Influence of Composition and Plastic Deformation on the Hydrogen Internal Friction Peak in Amorphous Co-Zr Alloys
}

\author{
F. Winter, S. Adam and H.-R. Sinning \\ Institut für Werkstoffe, Technische Universität Braunschweig, Langer Kamp 8, 38106 Braunschweig, \\ Germany
}

\begin{abstract}
Vibrating-reed measurements of the hydrogen internal friction peak were performed on a series of Co- $\mathrm{Zr}$ glasses ranging from $\mathrm{Co}_{55} \mathrm{Zr}_{45}$ to $\mathrm{Co}_{24} \mathrm{Zr}_{76}$. Variations in peak shape and growth behaviour (on increasing the $\mathrm{H}$ concentration) were observed for different alloy compositions, together with an increase of the average activation energy with cobalt concentration. These findings can be explained by the interstitial reorientation mechanism, assuming reorientation jumps of the $\mathrm{H}$ atoms between $\mathrm{Zr}_{4}$ tetrahedra; the activation energy increase then reflects the increase of the average $\mathrm{Zr}$ - $\mathrm{Zr}$ nearest neighbour distance with Co concentration known for this system. In Co${ }_{55} \mathrm{Zr}_{45}$, two peaks were detected under certain H-charging conditions, possibly as a result of a chemical decomposition. After cold-rolling, additional IF peaks appear superimposed on the hydrogen peak (with large scatter), but can be distinguished as separate processes by a different annealing behaviour.
\end{abstract}

\section{INTRODUCTION}

Almost two decades after the first discovery of a hydrogen-induced internal friction (IF) peak in a metallic glass [1], the effect is still not yet fully understood, in spite of a large body of experimental and theoretical work published on this issue (see e.g. reviews [2-5]). Within the general interpretation as an interstitial reorientation process (analogous to the Snoek relaxation in crystalline metals), it is still an unsolved problem how, in the disordered amorphous structure, the individual contributions of the $\mathrm{H}$ atoms superimpose to give the macroscopic relaxation strength and activation energy spectra [6]. Fermi-Dirac occupation statistics [7], blocking effects [8], and the interrelated distributions of atomic distances, site and saddle-point energies [9] are ingredients to this problem. It is evident that systematic experimental data on the change of relaxation parameters with structure, e.g. as a function of composition in a binary alloy system, would be very helpful in this context. However, in spite of the large overall number of observations, such systematic data practically do not yet exist.

Another complicating aspect was introduced by the recent discovery of apparently similar relaxation peaks in plastically deformed metallic glasses [10,11]. This led Khonik and Spivak [12] to assume a common origin of both effects, which is at variance with the usual interpretation of the hydrogen peak mentioned above. Clarifying experimental results on the superposition of deformation and hydrogen effects in further amorphous alloy systems should be the best way to resolve this controversy.

The present paper should be understood as a first step to provide such systematic data, in preliminary form, on both of these aspects. The system $\mathrm{Co}-\mathrm{Zr}$ has been chosen because extensive results on the hydrogen relaxation already exist for the composition $\mathrm{Co}_{33} \mathrm{Zr}_{67}[5,6,13,14]$.

\section{EXPERIMENTAL PROCEDURE}

The experiments were performed on melt-spun amorphous ribbons with compositions from $\mathrm{Co}_{55} \mathrm{Zr}_{45}$ to $\mathrm{Co}_{24} \mathrm{Zr}_{76}$, with initial, "quenched-in" hydrogen concentrations of some $10^{-3} \mathrm{H} / \mathrm{M}$ as determined by vacuum extraction analysis. Internal friction $\mathrm{Q}^{-1}$ and resonance frequency $f$ (normally near $300 \mathrm{~Hz}$ ) were measured repeatedly at a heating rate of $2 \mathrm{~K} / \mathrm{min}$, using the vibrating-reed technique. Between successive measurement cycles, the samples were subjected to thermal treatments or charged with hydrogen from the gas phase (at $300-530 \mathrm{~K}$ and $0.05-30 \mathrm{MPa} \mathrm{H}_{2}$ ) while remaining clamped in the vibrating-reed holder; series of damping peaks with increasing $\mathrm{H}$ concentration were thus obtained on the same sample. Activation energy spectra were calculated using a numerical deconvolution procedure [15]. 
To study the influence of plastic deformation, some ribbons of amorphous $\mathrm{Co}_{33} \mathrm{Zr}_{67}$ were cold rolled using a special miniature rolling mill [16]. The initial ribbon thickness of about $35 \mu \mathrm{m}$ was reduced by 2 to $12 \mu \mathrm{m}$, corresponding to relative thickness reductions between 5 and $33 \%$.

\section{INFLUENCE OF ALLOY COMPOSITION}

As known from many related studies, also in Co-Zr glasses the hydrogen IF peak grows and shifts to lower temperatures with increasing $\mathrm{H}$ concentration. However, the details of this peak growth depend on alloy composition (Fig. 1): whereas for $\mathrm{Co}_{24} \mathrm{Zr}_{76}$ the high-temperature flank of the broad and asymmetric peak remains approximately unchanged (Fig. 1 b), there is a decay of the high-temperature side in alloys more rich in cobalt, like $\mathrm{Co}_{45} \mathrm{Zr}_{55}$ (Fig. $1 \mathrm{a}$ ), where the peak is somewhat narrower and less asymmetric. Similar tendencies also follow from a comparison of deconvoluted activation energy spectra between $\mathrm{Co}_{24} \mathrm{Zr}_{76}$ and $\mathrm{Co}_{33} \mathrm{Zr}_{67}[17]$ not shown here for reasons of space.
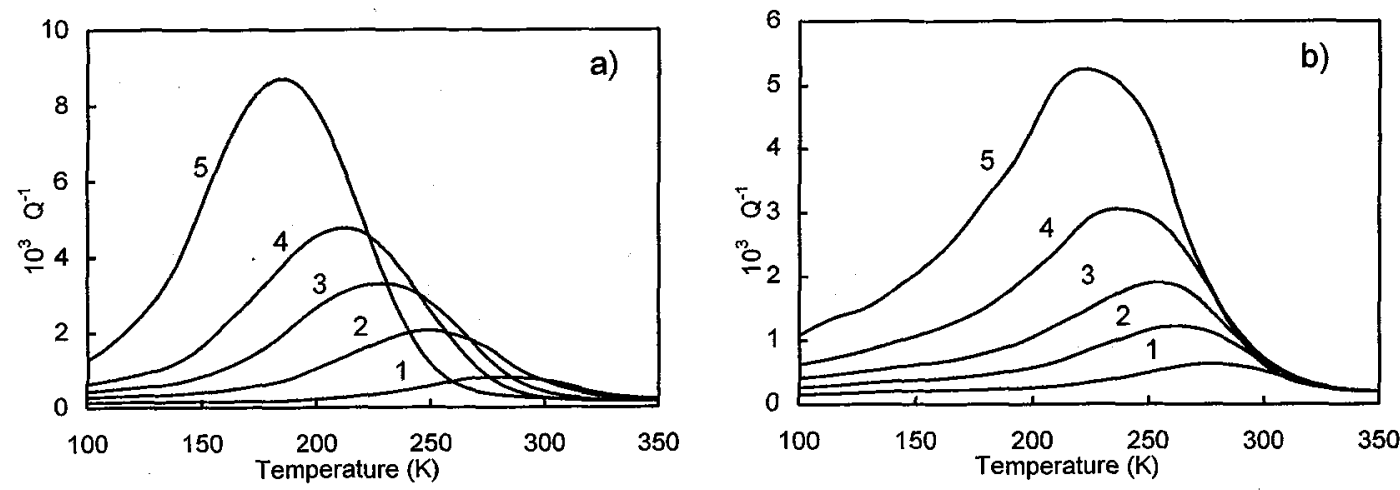

Figure 1: Two examples for the growth of the IF peak in Co-Zr glasses with hydrogen concentration, starting from preannealed samples $\left(2 \mathrm{~K} / \mathrm{min}\right.$ to $\sim 600 \mathrm{~K}$, curves 1) with the "quenched-in" $\mathrm{H}$ content of about 0.3 at $\%$. a) $\mathbf{C o}_{\mathbf{4 5}} \mathbf{Z r}_{\mathbf{5 5}}: \mathrm{f}=220$

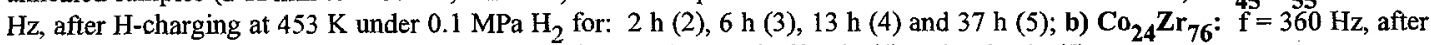
$\mathrm{H}$-charging at $473 \mathrm{~K}$ under $0.06 \mathrm{MPa} \mathrm{H}_{2}$ for: $15 \mathrm{~min}$ (2), $30 \mathrm{~min}(3), 60 \mathrm{~min}$ (4) and $120 \mathrm{~min}$ (5).

An exceptional behaviour was observed in the most cobalt-rich glass, $\mathrm{Co}_{55} \mathrm{Zr}_{45}$ (Fig. 2): after hydrogen charging at a rather high temperature of $523 \mathrm{~K}$, two IF peaks appear above a certain $H$ concentration (which is neither found in the more Zr-rich alloys nor in the same alloy after charging at only $453 \mathrm{~K}$ ). Since it is known for Co-Zr that a chemical decomposition into two amorphous phases takes place in alloys containing more than $60 \mathrm{at} \%$ Co [18], it may be imagined that under the $\mathrm{H}$ charging conditions of Fig. 2 this decomposition range is extended to include also $\mathrm{Co}_{55} \mathrm{Zr}_{45}$. More direct evidence on this latter point should be awaited before discussing the double-peak behaviour in Fig. 2 in more detail.

If the interstitial reorientation mechanism is responsible for the observed IF peaks, the thermally activated jump of the $\mathrm{H}$ atom between tetrahedral sites surrounded by four $\mathrm{Zr}$ atoms should be the basic relaxation event in $\mathrm{Zr}$-based amorphous alloys [5,6]. Applying the theoretical expressions of Richards [9] to this situation, the activation energy of a single jump can be written as

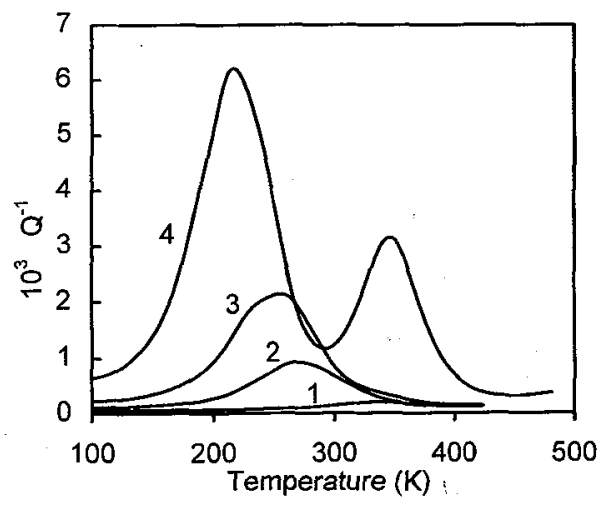

Figure 2: Growth of two IF peaks in $\mathrm{Co}_{55} \mathrm{Zr}_{45}$ after $\mathrm{H}$-charging at $523 \mathrm{~K}$ under $0.1 \mathrm{MPa} \mathrm{H}_{2}$ : (1) annealed sample, (2) $1 \mathrm{~h}$, (3) $2 \mathrm{~h}$ and (4) $4 \mathrm{~h}$ charging time.

$$
\mathrm{E}_{\mathrm{a}}=\mathrm{U}_{0 \mathrm{~S}}-\mathrm{U}_{0 \mathrm{E}}+3\left(\mathrm{a}_{\mathrm{S}}-2 \mathrm{a}_{\mathrm{E}}\right)+\left(\mathrm{a}_{\mathrm{E}^{-} \mathrm{a}_{\mathrm{S}}}\right)\left(\mathrm{d}_{1}+\mathrm{d}_{2}+\mathrm{d}_{3}\right) / \mathrm{d}_{0}+\mathrm{a}_{\mathrm{E}}\left(\mathrm{d}_{4}+\mathrm{d}_{5}+\mathrm{d}_{6}\right) / \mathrm{d}_{0},
$$

where $d_{1}$ to $d_{3}$ are the distances between the three $Z r$ atoms surrounding the saddle point position, and $d_{4}$ to $d_{6}$ are the other three edges of the tetrahedron. $U_{0 E}$ and $U_{O S}$ are the saddle-point and equilibrium (i.e. "site") energies of a $\mathrm{H}$ atom jumping out of a regular tetrahedron with a reference edge length $\mathrm{d}_{0}$; $\mathrm{a}_{\mathrm{S}}$ and $a_{E}$ contain the respective hydrogen-metal forces: Assuming $a_{S} / a_{E}=1.5$ [19], Eq. (1) simplifies to 


$$
\mathrm{E}_{\mathrm{a}}=\mathrm{U}_{0 \mathrm{~S}}-\mathrm{U}_{0 \mathrm{E}}-3 \mathrm{a}_{\mathrm{E}} / 2+\left(\mathrm{a}_{\mathrm{E}} / \mathrm{d}_{0}\right)\left[\mathrm{d}_{4}+\mathrm{d}_{5}+\mathrm{d}_{6}-\left(\mathrm{d}_{1}+\mathrm{d}_{2}+\mathrm{d}_{3}\right) / 2\right] .
$$

From the expression in square brackets, it follows that with overall increasing $\mathrm{Zr}$ - $\mathrm{Zr}$ distances, the average activation energy of the $\mathrm{H}$ relaxation should increase, too. As Fig. 3 shows, this theoretical prediction is indeed confirmed - for the first time - by the experimental results in the Co- $\mathrm{Zr}$ system at low $\mathrm{H}$ concentration (taking the peak temperature as a measure of activation energy). Moreover, if the peak height is taken as a measure of $\mathrm{H}$ concentration, a comparison between $\mathrm{Co}_{33} \mathrm{Zr}_{67}$ and $\mathrm{Co}_{24} \mathrm{Zr}_{76}$ yields this behaviour even over the entire range of $\mathrm{H}$ concentrations up to values near $1 \mathrm{H} / \mathrm{M}$ (cf. [5,6]), see Fig. 4. The latter, however, seems not to be true for glasses more rich in cobalt showing a stronger peak shift with $\mathrm{H}$ concentration; such measurements are still in progress.

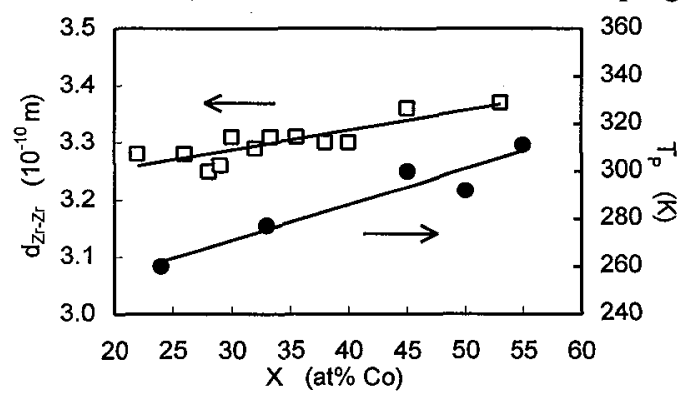

Figure 3: Comparison of the IF peak temperature $T_{p}$ for $\mathrm{Co}_{\mathrm{X}} \mathrm{Zr}_{1-\mathrm{x}}$ glasses at low (i.e. quenched-in) $\mathrm{H}$ concentration (peak height $Q_{p}^{-1}=5 \cdot 10^{-4}, f=300 \mathrm{~Hz}$ ) with the average $\mathrm{Zr}-\mathrm{Zr}$ nearest neighbour distance (after Steyer et al. [20]) as a function of cobalt concentration $x$.

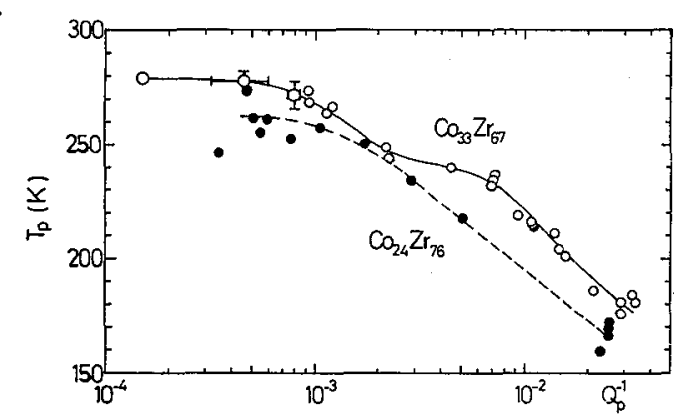

Figure 4: Peak temperature $T_{p}$ at $f=300 \mathrm{~Hz}$ as a function of the peak height $Q_{p}^{-1}$ (after background subtraction), for the $\mathrm{H}$-induced IF peaks in $\mathrm{Co}_{24} \mathrm{Zr}_{76}$ (closed symbols) and $\mathrm{Co}_{33} \mathrm{Zr}_{67}$ (open symbols).

The above theoretical considerations following Richards [9] strictly apply only to dilute $\mathrm{H}$ concentrations in monoatomic model glasses with geometrically similar tetrahedral sites (i.e. correlated site and saddle-point energies). In the Co-Zr system, deviations should be expected at the lower $\mathrm{H}$ concentrations the higher the Co content is, due to the lower number of sites with pure $\mathrm{Zr}$ surroundings that are preferred by the $\mathrm{H}$ atoms. For the same reason, also the suppression of reorientation events by blocking effects should begin at comparatively lower $\mathrm{H}$ concentration in the Co-rich case, as discussed in more detail elsewhere [6]. This might explain the different peak shape and growth characteristics between $\mathrm{Co}_{45} \mathrm{Zr}_{55}$ and $\mathrm{Co}_{24} \mathrm{Zr}_{76}$ observed above in Fig. 1 .

\section{INFLUENCE OF PLASTIC DEFORMATION}

In the Co-Zr glasses, any damping effect due to a plastic deformation can only be observed in addition to the hydrogen peak: the chemical affinity between $\mathrm{H}$ and $\mathrm{Zr}$ is so strong that it is impossible to remove the "quenched-in" $\mathrm{H}$ content, and hence the resulting IF peak, by any treatment that does not destroy the amorphous state itself.

As exemplified in Fig. 5, the internal friction results on cold-rolled $\mathrm{Co}_{33} \mathrm{Zr}_{67}$ are subject to unexpectedly large scatter: in some samples, there seems to be no significant deviation from the "undeformed" hydrogen peak, whereas in other samples drastic changes occur. The latter, although observed only in part of the samples, may roughly be divided into three effects:

- a large peak (up to a factor of 5 higher) at the temperature of the original hydrogen peak $(\sim 280 \mathrm{~K})$,

- a shoulder at the low-temperature side of this peak $(\sim 220 \mathrm{~K})$,

- an additional, small low-temperature peak $(\sim 125 \mathrm{~K})$.

Owing to the extreme scatter, it is difficult to find out a dependence of these effects on the degree of deformation: what can be said is that mainly the maximum deviations from the undeformed behaviour, and hence the scatter, increase with the relative thickness reduction. This leads, in a linear least-squares fit, to an overall increasing tendency of peak height with thickness reduction [17].

In contrast to this poorly reproducible behaviour of as-rolled samples, all deformation effects were removed by annealing treatments appropriate to structural relaxation of the amorphous state. This is demonstrated in Fig. 6 for one of the more pronounced, deformation-induced damping spectra of Fig. 5, which is reduced completely to the residual, "quenched-in" hydrogen peak. The tendency of increasing peak height with thickness reduction (least-squares fit) also disappears after annealing [17].

On the other hand, it is known for this glass that IF peaks produced by higher hydrogen concentrations, as high as the largest deformation peaks in Fig. 5, are not reduced in height by such annealing 
treatments [13]. Hence, the damping effects produced in amorphous $\mathrm{Co}_{33} \mathrm{Zr}_{67}$ by plastic deformation and by hydrogen, respectively, appear as separate processes that can be distinguished by a different annealing behaviour.

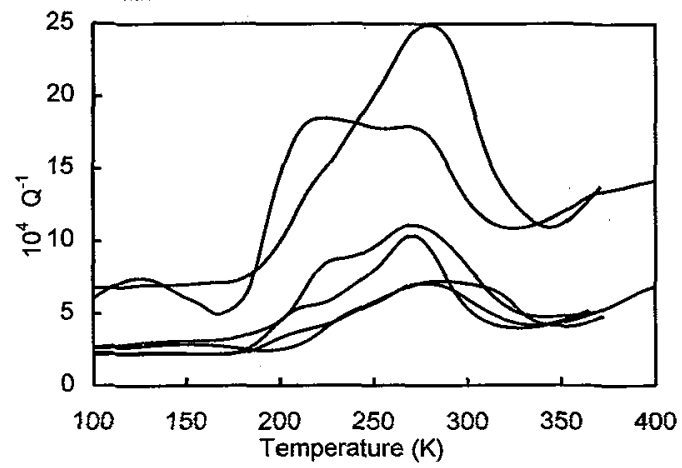

Figure 5: Internal friction of some $\mathrm{Co}_{33} \mathrm{Zr}_{67}$ samples after cold rolling to thickness reductions between 10 and $33 \%$ (frequency $190-550 \mathrm{~Hz}$ ).

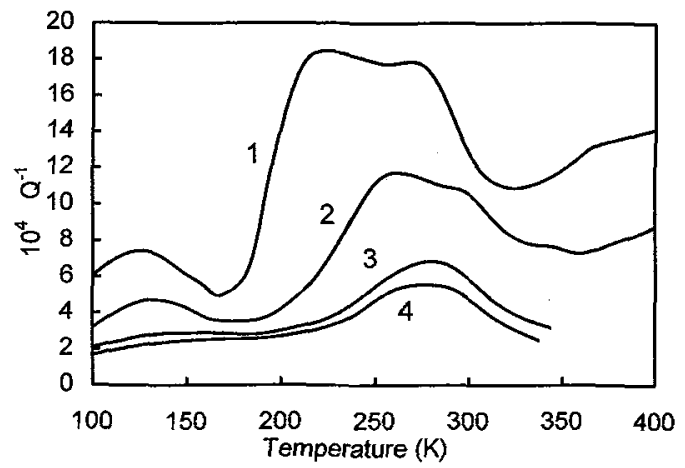

Figure 6: Annealing behaviour of one of the damping spectra from Fig. 5 (thickness reduction $20 \%$, frequency 340-380 Hz): as-rolled state (1) and measurements after heating with $2 \mathrm{~K} / \mathrm{min}$ to $473 \mathrm{~K}(2), 583 \mathrm{~K}(3)$, and $612 \mathrm{~K}$ (4).

\section{CONCLUSIONS}

The results of the present study do not support ideas of a common origin of hydrogen and deformation IF peaks in metallic glasses [12], but confirm the conventional interpretation of the hydrogen effect as an interstitial reorientation process. The observed variation of the hydrogen relaxation with alloy composition reflects the influences of topological and chemical short-range order on this relaxation process, and underlines the possible application of "mechanical hydrogen spectroscopy" as a probe [5]. However, the results also show that any $\mathrm{H}$-induced IF spectra must be checked carefully for superimposed, unwanted deformation effects.

Acknowledgments. We wish to thank G. Steckler for his help in all experimental questions. The amorphous Co-Zr ribbons were kindly supplied by D. Plischke of Göttingen University. Financial support by the Deutsche Forschungsgemeinschaft is gratefully acknowledged.

\section{References}

[1] Berry B.S., Pritchet W.C. and Tsuei C.C., Phys. Rev. Lett. 41 (1978) 410.

[2] Berry B.S. and Pritchet W.C., in Hydrogen in Disordered and Amorphous Solids, G. Bambakidis and R.C. Bowman Eds. (Plenum Press, New York 1986) p. 215.

[3] Mazzolai F.M., Z. Phys. Chemie Neue Folge 145 (1985) 199.

[4] Yoshinari O. and Koiwa M., in Mech. Spectroscopy, L.B. Magalas Ed. (Chapman and Hall), to be published.

[5] Sinning H.-R., Defect Diffusion Forum 123-124 (1995) 1.

[6] Sinning H.-R., phys. stat. sol. (a) 140 (1993) 97.

[7] Kirchheim R., Acta metall. 30 (1982) 1069.

[8] Switendick A.C., Z. Phys. Chemie Neue Folge 117 (1979) 89.

[9] Richards P.M., Phys. Rev. B 27 (1983) 2059.

[10] Zolotukhin I.V., Belyavskii V.I., Khonik V.A. and Ryabtseva T.N., phys. stat. sol.(a) 116 (1989) 255.

[11] Khonik V.A., J. Alloys Comp. 211/212 (1994)114.

[12] Khonik V.A. and Spivak L.V., Acta mater. 44 (1996) 367.

[13] Sinning H.-R., J. Phys.: Condensed Matter 3 (1991) 2005.

[14] Sinning H.-R. and Matz N., in Ordering and Disord. in Alloys, A.R.Yavari Ed. (Elsevier, London 1992) p. 364.

[15] Adam S., diploma thesis, Technical Univ. Braunschweig 1994.

[16] Haeßner F. and Speitling A., Z. Metallkunde 74 (1983) 763.

[17] Winter F., diploma thesis, Technical Univ. Braunschweig 1996.

[18] Gärtner F., doctorate thesis, Univ. Göttingen 1992.

[19] Sinning H.-R., Phys. Rev. B 46 (1992) 5989.

[20] Steyer M., Krebs H. U. and Freyhardt H.C., Z. Phys. B 66 (1987) 317. 